\title{
El sociograma de la prostituta en la obra latina La Suegra: una aproximación sociocrítica
}

\author{
The Sociogram of the Prostitute in the Latin Play The Mother in Law: A Social- Critical Approach
}

\author{
Andrey Gómez Jiménez' \\ Mailyn Madrigal Abarca²
}

Fecha de recepción: 26-5-2019

Fecha de aprobación: 16-9-2019

\begin{abstract}
Resumen
En este artículo se estudia la obra dramática latina La Suegra de Terencio con el fin de analizar la construcción del sociograma de la prostituta. Para ello, este texto se basa en la postura del autor como sujeto transindividual, para luego determinar si la construcción analizada, es decir el conjunto de elementos que constituyen la caracterización de la hetera, es reinscrita o se mantiene. Se tomaron como objetos de estudio los diálogos establecidos por Baquis, Sira y Filotis con el resto de personajes.
\end{abstract}

Palabras clave: Comedia Latina, La suegra, prostituta, Sociocrítica, sociograma de la prostituta.

\begin{abstract}
In this article, it is studied the Latin dramatic text The Mother- in- Law by Terence in order to analyze the construction of the prostitute's sociogram. For that reason, this text is based on the author's position such as trans-individual subject; then it determines if the construction analyzed, in other words the set of elements that constitute the characterization of the hetera, is rewritten or maintained. Objects of study were taken such as established dialogues by Baquis, Sira y Filotis with the rest of the characters.
\end{abstract}

Key Words: Latin comedy, The Mother- in- Law, prostitute, Socio- critical, prostitute's sociogram.

\footnotetext{
1 Estudiante de IV año de la Carrera Enseñanza del Castellano y Literatura. Universidad de Costa Rica, Sede de Occidente, Costa Rica. Correo electrónico: andrey.gomez.jimenez@est.una.ac.cr

2 Estudiante de IV año de la Carrera Enseñanza del Castellano y Literatura. Universidad de Costa Rica, Sede de Occidente, Costa Rica. Correos electrónicos: mayaba2004@hotmail.com
} 


\section{Introducción}

Este artículo tiene el propósito de analizar la figura de la prostituta, en la obra Hecyra (La suegra) de Terencio, publicada en el año 165 a.C., a partir de una perspectiva sociocrítica. Obra donde la cual el dramaturgo desempeña el papel de sujeto transindividual.

Bajo la visión teórica indicada, se estudiarán las características que conforman el personaje de la prostituta en la obra latina y posteriormente compararla con el grupo de cualidades estereotipadas con las cuales se le reconoce.

Para llevar a cabo este análisis es necesario identificar las concepciones que tiene el personaje "Baquis" dentro de la comedia de Terencio, ya que conocer su percepción y reconocer su actuación dentro del texto, permitirá determinar si a partir de su comportamiento y de sus cualidades se (re)inscribe la figura de la prostituta que este personaje representa.

Es importante señalar que este trabajo no pretende ocupar posición ante la discusión crítica de la obra de Terencio, donde en este caso, ha existido un antiguo debate sobre catalogar a la prostituta como bona meretrix, o mala meretrix, discusión que amplía Navarro (2016) en su estudio. El objetivo propuesto en este análisis está únicamente enfocado en la comparación del sociograma de la prostituta en la Hecyra con respecto a otros.

\section{Aproximaciones analíticas sobre la prostituta}

La prostitución ha sido un tópico en múltiples investigaciones, en las cuales se han tratado aspectos como: su proceder, razones de existir, categorías y condiciones de vida, sin dejar de lado su estado legislativo y concepción social. El oficio del sexo, según Herreros y Santapau (2005) y Montalbán (2016), cultiva en una sociedad patriarcal una concepción ambivalente de la profesión, en la cual se concentra la aceptación del oficio por ser necesario para el desarrollo sexual del hombre y, al mismo, tiempo salvaguardar la integridad de la mater, ideal de mujer y esposa romana, al cual toda muchacha pura y casta debía aspirar. Herreros y Santapau (2005, p. 98), aluden a la hipocresía social romana con las siguientes palabras:

Lo cierto es que la figura de la prostituta romana, a la que a menudo se veía caminar por las calles de la ciudad era muy aceptada. A priori los hombres despreciaban a las prostitutas porque eran mujeres bajas, sucias, inmorales y amorales, comerciantes de su cuerpo... que nada tenían que ver con las mujeres puras y castas que ellos tenían en casa (y con las que se casaban). Sin embargo eran esos mismos hombres los que las utilizaban, los que contrataban sus servicios alegremente y sin remordimientos.

Si bien, la prostitución fue desaprobada por la perspectiva conservadora de Roma, la profesión de la hetera, resultó indispensable para mantener a salvo a las mujeres decentes, de los delitos de adulterio o estupro, pues los ciudadanos romanos encontraban en las prostitutas el desahogo sexual que hubieran descargado en las mujeres casadas o aspirantes a la unión del matrimonio, el cual se consideraba un mal necesario para el bienestar de la sociedad.

La prostitución, como práctica lucrativa, motivó a que mujeres en condiciones particulares optaran por dedicarse al oficio. Montalbán (2016), detalla algunas de las razones que condujeron a estas féminas a encontrar en su cuerpo la fuente principal de ingresos. Aunque, la prostitución también fue un medio de emancipación femenina, puesto que, muchas mujeres de clase alta, libres o casadas, encontraron en esta actividad un estilo de vida más autónomo y/o una libertad sexual que fue negada en la unión conyugal.

El mismo investigador también explica múltiples categorías que permiten diferenciar en el contexto romano la situación social de las prostitutas y su estado económico. La primera categoría corresponde a la de cortesana; prostituta de lujo, generalmente independiente, la cual tenía posibilidades de definir el precio por sus servicios, establecer contratos a largo plazo con sus clientes, 
mantener una clientela estable y despreciar a otros. Las prostitutas de este tipo solían atender los clientes en sus casas, además, tenían posibilidades de establecer el concubinato al abandonar su antiguo estilo de vida.

En segundo lugar, se encuentran las prostitutas mesoneras o venteras, mujeres que, además de realizar los trabajos en tabernas, prestaban servicios sexuales bajo el consentimiento del esposo, el cual jugaba el papel de proxeneta, cuando estas eran casadas. Finalmente, la última categoría es la correspondiente a las prostitutas de bajos fondos, estas se encontraban bajo el dominio de un leno (proxeneta) y ejercían el oficio en condiciones insalubres. En el estudio de Montalbán (2016) se expone la manipulación de la hetera como propiedad del leno, cuando estas conformaban parte del último grupo de prostitutas descrito. Donde el "cuidador" recibía el derecho de determinar las tarifas por sus servicios.

Partiendo de lo referido por los autores Montalbán, Herreros y Santapau, la contraproducente realidad de las heteras no acababa con las exigencias y malas condiciones en las que desempeñaban sus labores, sino que se enfrentaban a un panorama más crítico al descubrir su situación social. La prostitución fue un oficio deseado y considerado indispensable para el bien de la sociedad romana, sin embargo, condenatorio para quien lo ejercía. La prostituta carecía de derechos sociales, pues las heteras se consideraban una "no mujer", un ser impúdico, cuyo comportamiento sexual resultaba anómalo por asumir prácticas sexuales inaceptables y un rol sexual activo.

McGinn (1998), citado en Montalbán (2016), menciona que la meretrix se podía definir por los siguientes aspectos: promiscuidad, pago e indiferencia emocional. La hetera se convirtió en una antítesis de la mujer romana por representar todo lo opuesto al ideal patriarcal. Este tipo de profesionales tenía acceso a los lugares vedados a la mujer promedio, como lo eran las reuniones públicas y exclusivamente masculinas, debido a que eran acompañantes, además, tenían la posibilidad de realizar prácticas prohibidas como beber vino. Es a través de su actuar desvergonzado, caracterizado por la insensibilidad, su interés económico y figurada independencia que se le consideró un ser transgresor.
Otros investigadores, entre los cuales cabe destacar a Herreros y Santapau (2005), señalan la desvalorización sufrida por la prostituta en materia legal, al demostrar la desigualdad de condiciones que sufría frente a la mujer romana decente, puesto que, en algunos casos quedaba excluida de la institución del matrimonio, incluso cuando cumplía con los requisitos para aspirar a tal empresa, como ser libre y ciudadana romana. La hetera quedaba fuera de la institución matrimonial por pertenecer a la clase social de los infames, además de tener anulada, a su vez, la posibilidad de recibir herencias. No obstante, el mismo modelo legal romano que las desprotegía estableció el cobro de impuestos por su trabajo.

En el ámbito literario Fernando Souto Delibes (2002) realiza un repaso del papel de la prostituta en diferentes épocas, a través del análisis de las comedias antiguas, media y nueva. El estudioso señala que en la comedia antigua empiezan a aparecer obras tituladas con el nombre propio de prostitutas, en las cuales las heteras son utilizadas para desacreditar a personas de alto rango social o político; se les otorga a las profesionales del sexo un papel secundario dentro de los textos literarios, por no gozar de verdadero protagonismo y limitar su aparición al desprestigio de otros.

No obstante, y a pesar de su aparición secundaria y casi insignificante en la comedia antigua, Souto (2002) señala que la escueta mención de las heteras sirvió para obtener datos acerca de ellas, como por ejemplo, su precio, y por ende, su calidad; sin dejar de lado su exacerbado libido, vanidad y talentos musicales.

El investigador indica que los lugares más frecuentados por las heteras eran los banquetes, pues eran consideradas elementos de entretenimiento en reuniones públicas y otros lugares de dominio masculino, en los cuales la mater no era bienvenida, haciéndose natural la hostilidad de las mujeres decentes hacia ellas.

En cuanto a la comedia media, el estudioso argumenta que las obras con nombres de prostitutas persisten, quedando en evidencia que es en este tipo de textos en el que mayor protagonismo se le concede a la meretrix. En estas comedias la hetera no aparece con un papel 
secundario y su función exclusiva es desprestigiar a un político o personaje importante. En este periodo la prostituta se convierte en el eje central de la trama y se presenta como un personaje autónomo. Aunque, en cuanto a sus características, no aparecen variantes considerables, sino que se mantienen siendo la avaricia y la desgracia económica (despilfarro de dinero por parte del cliente para saciar sus caprichos), factores intrínsecos a la profesión.

La aparición de la prostituta se hace en banquetes y fiestas, solamente que el consumo de alcohol no es exclusivo de las viejas, sino que el vicio es general y se convierte en un aspecto característico de cualquier mujer dedicada al oficio, sumándose a este el comportamiento lujurioso de la hetera, el cual refuerza el rasgo de perversión de la misma, mediante comparaciones con animales o criaturas mitológicas. No obstante, el especialista tras exponer la pérdida económica que representa mantener relaciones constantes con una hetera, también comenta la preferencia masculina por establecer mayor contacto con las mujeres expertas en sexo que con sus legítimas esposas, evidenciándose una perspectiva más positiva de la prostituta en la comedia media.

El aspecto que enlaza el fin del periodo de esta comedia y el inicio de la comedia nueva, es la aparición del personaje de la pseudo hetera, esta figura se caracteriza por ser una joven de buena procedencia, obligada a prostituirse por la realidad que atraviesa tras verse desprotegida, pues durante su infancia fue abandonada o secuestrada. Sin embargo, su futuro se tornará positivo tras conocerse su verdadero origen y hacerse posible su rehabilitación.

En la comedia nueva disminuye la aparición de comedias tituladas con nombre de cortesanas, aunque su caracterización persiste tal y como se presenta en las comedias precedentes. La potestad de hablar de sí mismas les permitirá exponer, según el último estudioso citado, sus miserias.

Mediante el análisis de Souto (2002), se determinan aspectos prevalecientes y comunes en las tres comedias que definen a la hetera, entre los cuales se encuentran la juventud como un periodo de dicha para la hetera y que señala como enemigo a la vejez, la lujuria y la avaricia como aspectos intrínsecos del oficio, además del talento musical como arte de entretenimiento en las actividades exclusivamente masculinas, entre estas, el banquete.

En suma, se determina que uno de los estudios descritos en este apartado caracteriza a la prostituta desde una perspectiva histórica. Mientras que otro se inclina por exponer el contexto legal en el que se encontraban las profesionales del sexo y la última fuente, proporciona una visión literaria de la figura de interés.

\section{Aspectos teóricos}

Una vez revisados los estudios sobre la hetera y rescatadas sus caracterizaciones dentro del discurso social y literario, resulta importante establecer la conexión entre sociedad - texto, para la cual es imprescindible la Sociocrítica, teoría que busca el enfoque social-histórico de las obras, partiendo de las mismas como objeto de estudio. Para efectos de esta teoría no interesa en absoluto la relación sociedad-texto, "el contenido no es portador de la significación social de un texto de ficción” (Cros, 1986, p. 70), al contrario, lo importante son las relaciones entre las estructuras de la realidad y la estructura de la ficción.

Esta conexión entre estructuras sociales y literatura toma vida cuando el escritor decide representar el mundo en un texto de ficción. No obstante, como afirma Cross (1996), esto no quiere decir que la ficción tenga una conexión directa con la sociedad, al contrario, los textos y sus contenidos nunca representan la realidad, al menos de forma explícita.

Para dilucidar esta relación sociedad - texto, es necesario comprender cómo el autor crea el mundo del texto con base en los discursos sociales, recoge los elementos de este último y los distribuye en la obra ficcional; entendiendo por discurso y de manera sencilla, lo llegado al oído del hombre en las sociedades (Robin y Angenot, 1991). En segundo lugar, es preciso entender cómo estos discursos sociales están configurados en una pluralidad temática sumamente confusa, por lo tanto, es difícil descifrarlos y comprenderlos por sí mismos. Finalmente, cuando el autor "traslada" esa realidad basada en ese rumor social hacia la ficción, los teóricos concuerdan en que la realidad sufre una transformación semiótica o de sentido, es decir, 
el mundo del texto no representa el "mundo real", al contrario, el mundo del texto "contaminó" por medio de la escritura y la ficción lo dicho del "mundo real", de ahí la imposibilidad del texto y sus contenidos para remitir directamente a la sociedad.

En cuanto al discurso, a pesar de que no tenga la capacidad para referirse de lleno a la realidad, este aún posee ciertas "huellas" remitentes a algunos elementos del mundo "real" (Robin y Angenot, 1991), y estos vestigios discursivos, como bien pueden ser la opinión, lo pensado, o sencillamente "lo dicho" están en un tipo conciencia compartida, la cual Cros (1986) llama sujeto transindividual, un sujeto compartido que pertenece a ciertos contextos socio-históricos y culturales de forma colectiva y no singular. Para el teórico esta noción engloba a todo ser humano, donde este posee un tipo memoria "inconsciente", una memoria producto de este sujeto cultural, y esta no existe como categoría individual. En otras palabras, todas las personas pertenecen a esta categoría, la cual corresponde a determinada época o contexto y este sujeto transindividual, atravesará todas las prácticas discursivas y textuales que un sujeto produzca.

Se concluye entonces que, el escritor, al estar inserto en la sociedad, es parte de un sujeto colectivo, compartiendo así elementos históricos sociales y culturales que influirán en su práctica, y al escribir logra una transformación de la realidad al decidir ocupar una posición singular de lo "decible" o "escribible" sobre lo que ha escuchado de ese discurso social, teniendo siempre en cuenta como este último está configurado dentro de un cuadro hegemónico o de poder, correspondiente a determinadas estructuras sociales.

Aclarado estos puntos, resulta valioso señalar que el sociograma de la sociocrítica es una categoría que permite entender la manera en que se articulan los discursos sociales en el texto literario. Según los investigadores Robin y Angenot (1991) se comprende como sociograma un cúmulo de tematizaciones que diferentes prácticas sociales inscriben en un sujeto en específico, se trata del conjunto de características discursivas las cuales conforman un objeto. En otras palabras, el sociograma es lo estereotipado de una figura social, lo adjudicado a esta por diferentes prácticas discursivas: ficción, prensa, discursos institucionales, ideológicos e incluso cotidianos. Es la puesta en escena de esos enunciados propios de una sociedad y periodo específico.

Para entender mejor la construcción del sociograma, según los teóricos citados, se debe comprender cómo está conformado por diversos hechos sociales y discursivos, los cuales son heterogéneos, difusos, inestables e incluso de orden omnipresentes difíciles de separar, por este motivo, esta noción procura una vista panorámica de estas significaciones englobando al signo o sujeto. Se trata de un tipo de esbozo de las múltiples características que rodean a la figura puesta en escena, la cual, como se ha venido mencionado, es un sujeto híper caracterizado en la sociedad (de ahí las concepciones del sociograma de la mujer, la prostituta y demás). Es importante mencionar cómo esta figura tendrá una función de núcleo, en el que giran alrededor todos estos hechos sociodiscursivos, esta noción en la teoría, se conoce como la fórmula predicativa del núcleo sociogramático. En otras palabras, esta fórmula está compuesta por ciertos elementos sociales y/o ficcionales que giran alrededor de un eje, para el cual se usa la metáfora de núcleo, siendo este la figura estereotipada. Cabe destacar que para Robin y Angenot (1991), el núcleo de un sociograma no tiene interés ni sentido, sino en diálogo con el debate general concentrado en torno a su estructura, es decir, en relación con una economía global de las representaciones sociales. Este concepto sociogramático resulta útil precisamente porque la figura de la prostituta de Terencio podrá ser puesta en diálogo con otras representaciones.

Hasta este punto, se ha hecho alusión al sociograma como un collage de signos, enunciados y elementos discursivos que lo configuran. No obstante, también se mencionó como este se debe estudiar en economía global y no individual. Robin y Angenot (1991) utilizan la metáfora de "nudo gordiano" para mostrar la complejidad de las representaciones que se le han asignado a dicho sociograma, representaciones intricadas, discordantes e incompatibles entre sí, y por lo tanto, no hay manera de extraer, separar y analizar. Como ya se mencionó anteriormente, estos elementos solo tienen sentido en interacción globalizada u holística, vistos como un todo. 
En síntesis, el sociograma es una especie de puente de lo discursivo a lo textual, esta noción se refiere a la conglomeración de diversos elementos textuales, sociales y discursivos que se han conferido a un sujeto característico de determinada época. Estas pluralidades de elementos adjudicados no pueden ser fraccionados para su estudio, al contrario, el sociograma solo tiene sentido desde una perspectiva general y global.

A modo de ejemplo, según los autores Robin y Angenot (1991), algunos hechos sociales que han influido en una elaboración de un sociograma de la prostituta van desde simples conversaciones, prejuicios y experiencias de todo tipo, hasta discursos más elaborados, como el de la oralidad masculina, el del desvío penal y del sexo, el médico administrativo y finalmente el discurso del higienista y del funcionario reglamentario. No obstante, en general, los escritores han recibido las tematizaciones de estos sujetos como mujeres vespertinas, ansiógenas, burlonas, cínicas, libertinas, alegradoras, condenatorias etc. En esta construcción, cabe señalar que intervienen todas las representaciones del sexo y de la mujer, es decir, problemas de género y patriarcado. Por todas estas razones, para los escritores es complicado desmontar la fórmula de ciertos sociogramas, al contrario, lo más común es que este termine reforzándolos y no desplazándolos de forma crítica (Robin y Angenot, 1991). Es importante destacar como los sociogramas, en este caso de la prostituta, propuesto en determinado ámbito literario, responderá a las necesidades de la literatura de su determinada época.

Abarcada ya la teoría, es de suma importancia preguntarse entonces cuál es el papel de la literatura operando sobre el discurso social, o de otro modo, ¿por medio de qué infiltraciones la literatura transforma o (re) inscribe el discurso? (Robin y Angenot, 1991). Para ello es necesario ver la postura del texto (o más bien la del autor transindividual, en este caso Terencio) ante el discurso, y observar qué sucede con el sujeto reconstruido a partir del material disperso en la sociedad. Según la sociocrítica, lo que puede hacer el escritor es (re)inscribir la fórmula predicativa del núcleo sociogramático, para situarse ya sea denunciándola, asumiéndola, desplazándola, transformándola, ironizándola, o bien, opacándola.
Es decir, si en la ficción un autor, por ejemplo, del siglo XIX sigue retomando y asignando características patriarcales y marginales a la "prostituta", este no está haciendo más que asumir la fórmula ya existente, pero si al contrario este presenta una mujer oprimida y sin derechos donde se invierten roles y estructuras sociales para evidenciar una marginalización, este estaría denunciado la fórmula predicativa del sociograma imperante. Claramente, para evidenciar qué sucede con un núcleo de este tipo, se debe hacer un análisis sumamente minucioso que estudie todas las categorías y mecanismos textuales donde dicha intervención se hace efectiva en el personaje, cuyo objetivo es el que se plantea en esta investigación. Está noción de sociograma, es entonces, la que permitirá analizar qué sucede con la (re)construcción de la figura de la prostituta a partir de las prácticas textuales en la que ha sido inscrita.

\section{Análisis}

En este análisis se procurará evidenciar los factores que interactúan y constituyen el sociograma de la prostituta, propuesto en el texto terenciano, para posteriormente definir cómo el sujeto transindividual (re)inscribe el sociograma, o bien, la fórmula predicativa del núcleo sociogramático.

Para analizar los factores que componen el sociograma, se realizarán dos fases, en la primera se expondrán todos los elementos propuestos por la perspectiva masculina, al respecto de la prostituta, asimismo, se identifica aquí la voz del varón como la voz de la sociedad, ya que se reconoce el contexto de la obra como un espacio de dominio patriarcal; mientras la segunda fase estará dedicada a exponer las características de la hetera terenciana, para comparar estas con los elementos discursivos que rodean a la fórmula predicativa de la prostituta de las comedias nuevas y medias de origen griego, que influyen en Terencio.

\section{Voz masculina - voz de la sociedad}

Terencio, entiéndase de aquí en adelante a este como sujeto transindividual, utiliza la voz masculina para exponer los principales rasgos atribuidos a la prostituta 
por la sociedad, pues según Herreros y Santapau (2005) hay tres aspectos que distinguen a la prostituta desde la perspectiva social de la época: la promiscuidad, la indiferencia y la avaricia. Desde la voz de Parmenón se comienzan a reforzar estas características, por ejemplo, se refiere a una de las causas que provocan el distanciamiento de Pánfilo en la relación mantenida con Baquis: "PARMENÓN.- [...] cuando Baquis le vio casado con otra, luego se le hizo más insolente y muy más pedigüeña." (Terencio, 1977, p. 153). A la figura de la hetera se le atribuyen actitudes de remarcado interés, según las autoras citadas, la necesidad de mantener su supervivencia provoca que la prostituta desarrolle un instinto rapaz. Es precisamente la confrontación de la institución del matrimonio con la prostitución, la causa por la cual Fedro y Laques consideran necesario que la prostituta se desentienda de Pánfilo para hacer efectivo el retorno de la esposa al lecho:

LAQUES.- Tú recibes en tu casa a mi hijo Pánfilo.

BAQUIS.- ¡Ah!

LAQUES.- Déjame decir [...].Él ya tiene una mujer, búscate tú otro amigo más seguro, mientras estas a tiempo de mirar por ti; porque ni él tendrá toda la voluntad, ni tú tampoco, en verdad, esa frescura (Terencio, 1977, p. 170).

A pesar de que no era mal visto frecuentar prostitutas después del matrimonio, la condición de Baquis representaba una amenaza para la relación, pues esta, anteriormente había mantenido un idilio con Pánfilo que había conducido al enamoramiento del joven. Según Herreros y Santapau (2005) a pesar de que las cortesanas eran mujeres de distinguida apariencia, seguían siendo prostitutas cuyo único objetivo era mantener a un hombre bajo su dominio hasta conducirlo a la decadencia económica, Baquis representaba un peligro para los jóvenes esposos, porque esta podría acabar con la relación de forma definitiva.

Un elemento por rescatar del diálogo mantenido entre la hetera y el padre de Pánfilo, es la voz masculina que le atribuye cierta importancia a la edad. Según Souto
(2002), la juventud para la prostituta representaba una garantía en el oficio, al desvanecerse la frescura de la mujer, estos sujetos pasaban a vivir bajo niveles de pobreza extrema, esto, si durante sus años de profesión no habían conseguido enamorar a un cliente, el cual les garantizará su manutención futura.

A pesar de que la caracterización de las prostitutas, desde la perspectiva romana, se les atribuye a los personajes masculinos; dentro de la obra es Sira quien las admite como propias, pues ella se dirige a Filotis para recomendarle que saque el máximo provecho de sus clientes, mostrando el menor escrúpulo: "SIRA. [...] no te duelas de ninguno; sino que peles, cercenes y despedaces al que te viene a las manos." (Terencio, 1977, p. 151). Es esta figura quien fortalecerá el concepto de trepadora, atribuido a la hetera. Sira asume la definición que deviene de un discurso masculino imperante en la doxa o pensamiento del momento.

\section{La voz de la prostituta}

Aunque Sira adopta, por medio del diálogo establecido con Filotis (Terencio, 1977, p. 151), los aspectos más sobresalientes de la prostituta según la sociedad, son las acciones de Baquis las que vendrán a contraponer lo establecido por la voz masculina y sumarán al sociograma elementos a su núcleo. Entre las actitudes asumidas por la hetera se encuentran la razonada comprensión y el agradecimiento con que responde la cortesana a los buenos tratos recibidos de su cliente: "Baquis. -Pero en verdad que por la codicia jamás tengo que inclinar mi voluntad a lo malo. Ya yo, mientras me fue lícito, goce de él benigno, gracioso y amoroso" (Terencio, 1977, p. 171). Este personaje viene a reformar la imagen de la prostituta con los aspectos de sensibilidad y desinterés.

Otro rasgo aportado por la amante de Pánfilo a la imagen de la prostituta es como esta comprende la posición en la cual se encuentra el personaje masculino. Resulta necesario señalar aquí, como también el afecto de Baquis sentido hacia su cliente resulta una contradicción con relación a su trabajo, porque la prostituta, según los autores citadas anteriormente, no mantenía un lazo afectivo con ningún varón; la empatía de Baquis es lo 
razón por la cual ella siente la necesidad de abogar por Pánfilo. La hetera lo expresa del siguiente modo: "Baquis. -Pero no quiero que tu hijo esté infamado falsamente, ni que vosotros, lo que no es razón, lo tengáis por inconstante sin culpa" (Terencio, 1977, p. 168). Son actitudes como las mencionadas anteriormente, las señaladas por Sira como debilidades del oficio, la intervención de Baquis en la vida de Pánfilo, se polariza con lo referido por su compañera.

Un aspecto fundamental del oficio de la prostitución es la discreción demandada. En la comedia, Baquis sigue construyendo una imagen positiva con el voto de silencio al no confesar la violación que Pánfilo cometió, siendo la reserva la última característica sumada a la figura de la cortesana en la comedia.

A pesar de que a lo largo de la obra, Terencio no alude en todas las escenas a la prostitución o a aspectos relacionados con el oficio, los espacios en los cuales las voces de las cortesanas tienen libre expresión, son dedicados a crear una defensa de su cliente, como ya se vislumbró en Baquis, o al referirse al maltrato recibido por el personaje. Filotis es quien al inicio de la comedia alude a las calamidades que tuvo que afrontar como cortesana de un soldado. Según Herreros y Santapau (2005) este tipo de hetera podía considerarse como una "prostituta de lujo", pues se alquilaba por el tiempo que el cliente lo deseará, ya fueran días, meses e incluso años, en los cuales esta tenía la obligación de ser fiel y estar bajo el mando del varón que la contrataba: "FILOTIS. - Apenas te podría decir Parmenón, el gran deseo que tenía de volver acá, de escaparme del soldado, [...] por gozar con libertad de vuestros convites, [...]; porque allí no podía hablar sino por tasa, lo que él le daba gusto. (Terencio, 1977, p. 151). Tal y como puede evidenciarse, a pesar de que Filotis pertenecía a la categoría más alta de hetera, esto no la libera de los peligros y los malos momentos de su profesión.

Todavía, cabe señalar que la prostituta se reconoce dentro de la obra de Terencio como un ser capaz de proporcionar alivio y alegrías. Baquis, dota de regocijo la vida de Pánfilo al reunir de nuevo a su familia, trae de vuelta a su esposa y a su hijo a la vida matrimonial previamente constituida, la prostituta, restituye la empresa de la familia.
Según Montalbán (2016), la hetera garantiza la integridad de las mujeres decentes (matronas y vírgenes), porque de esta manera se evitaba que los hombres atentaran contra la decencia de las matronas o de las mujeres listas para constituir una familia en su momento. A pesar de que en el texto, Baquis no logra evitar la violación de Pánfilo contra la muchacha, que más tarde sería su esposa, esta restituye a la familia a punto de disolverse, al confesar la verdad. Si bien el silencio a la hetera le hubiera garantizado el retorno de Pánfilo a su lecho, esta prefiere no guardar silencio y sacrificar el amor/interés por él.

Hasta este punto, los elementos que interactúan en este sociograma exponen la imagen de una prostituta cuya presentación viene a representar una amenaza para el orden social por interferir en el matrimonio, pero también se identifican predicados en los cuales puede considerársele un ser sensible, comprensivo, discreto, empático, portador de bienestar, sacrificado y agredido. Mediante esta amalgama de elementos puede concluirse que el sociograma propuesto por Terencio no se desvincula del establecido por la sociedad, sino que solo inserta una faceta positiva e ignorada de la prostituta.

Una vez definido el núcleo del sociograma elaborado en el texto, se debe responder a qué sucede con esta configuración; si es desplazada, transformada, denunciada, asumida, ironizada u opacada. Para realizar tal operación, se debe partir de otros sociogramas vigentes de la prostituta en ese entonces, por lo tanto, se tomaron en cuenta el sociograma ya descrito por Robin y Angenot y en principal, un estudio que muestra el papel de la prostituta en las comedias griegas, expuesto en el artículo de Souto (2002), las cuales son las que Terencio toma como base para elaborar sus textos paliatas, logrando observarse directamente los cambios en el proceso de imitatio del autor.

En el artículo de Souto (2002), se hace referencia a la desgracia que representa la prostituta para su amante, debido a todas las exigencias que manifiesta con el fin de mejorar su calidad de vida. Como ya se logró ver en el análisis, Terencio sigue reforzando este vector semántico de la prostituta avara, por medio de la voz masculina, característica también mencionada en el sociograma explicado por Robin y Angenot (1991). 
Las heteras de la comedia media aparecen igualmente citadas en su mayoría en interacción con los banquetes y el consumo desmedido de alcohol (Souto, 2002). Esta prostituta de "vida alegre" esta vez no es reforzada por Terencio, sino que esta característica en ellas es opacada en el sociograma de "La Suegra".

Otro aspecto, mencionado en el artículo de Souto (2002), es la vida banal y poco interesante de estas meretrices, descritas en la literatura de ese tipo. En la siguiente cita, el teórico, refiriéndose a las comedias de Antífanes, expone la vida de la trabajadora del sexo:

ella va y viene, va y se vuelve a marchar otra vez, viene, se queda, limpia, se encrema los ojos y nariz, se desmaquilla, se peina, sale del cuarto, se da un masaje, se baña, mira por la ventana, se viste, se perfuma, se pone las joyas, se aceita... (p.181)

En la Hecyra, Baquis no tiene exactamente una vida superflua, al contrario, tiene roles protagónicos, y como ya se demostró se presenta como una salvadora del orden social (matrimonio), además, esta monotonía no concuerda con una prostituta con voz, empática y que se expresa.

Otro carácter negativo de esta figura en las comedias medias, es la comparación entre estas mujeres y los animales mitológicos (Souto, 2002). Comedias como la de Anaxilas, son muestra de dicha afirmación, en este texto se señala que ninguna bestia salvaje es más devastadora que una meretriz. Concordando lo mencionado con anterioridad, con una de las características propuestas por Robin y Angenot (1991) en su sociograma; esta mujer es vista como una verdadera bestia del progreso social. Un ejemplo de estas comparaciones animalizadas se puede observar en una comedia de Anaxilas citada por el autor:

cualquiera que haya tenido alguna vez un affaire con una prostituta sería incapaz de nombrar una criatura más desordenada pues ¿qué dragón salvaje, qué Quimera con hálito de fuego o Caribdis o Escila tricéfala, ese monstruo del mar, o Esfinge, Hidra, leona, víbora y la familia alada de las Harpías ha tenido éxito alguna vez en sobrepasar tan abominable clase? No se puede. Esas mujeres sobrepasan todos los males ... (Souto, 2002, p. 182).

Esto presenta un contraste en la prostituta terenciana, esta figura en el texto no sufre de ninguna animalización, si bien mantiene rasgos negativos, como ya se discutió, en ningún momento por medio de metáforas o símiles se le animaliza, al contrario, se le humaniza por su sentido empático, sensible y comprensivo con sus clientes.

En cuanto a la Comedia Nueva, la cual tiene mayor relación con la comedia elaborada por Terencio, en general, se mantienen los mismos esquemas de la prostituta en la Comedia Media. "Se continúa así comparando a las heteras con animales." (Souto, 2002, p. 192). Las prostitutas siguen siendo también acreedoras de los mismos vicios, como la lujuria. Es normal en estas comedias ver a una hetera levantándose la falda en público, ver a otras jactándose de su trasero, y otras que simplemente se excitan con facilidad y expresan su apetito sexual. Nuevamente, esta lujuria y gran sexualidad es desplazada en la hetera de Terencio, donde no hay alusiones explicitas a su sexualidad, ni mucho menos comportamientos lujuriosos, al contrario, el lector conoce por el contexto la profesión de Baquis. No obstante, desde sus características psicológicas es difícil inferir su oficio de cortesana, debido a que, esta no se desenvuelve como las típicas prostitutas de las comedias griegas.

En general, y según el estudio de Souto (2002), en la comedia literaria griega siempre se presentará a la prostituta como símbolo de disputa y corrupción, facilitadora de los deseos inconfesables de los hombres, todas homogenizadas por sus características, completamente desdibujadas, lo que constituye un gran tópico en la literatura.

En la Comedia Nueva, la ramera tradicional se mantiene, aunque ya con menos importancia. Sigue siendo lujuriosa, avara y borracha, además continúa desenvolviéndose con facilidad en los banquetes (Souto, 2002). El experto citado anteriormente, concluye que la prostituta representará siempre algo negativo, una mujer capaz de pervertir todo lo que toca. No obstante, esta figura se llega a convertir 
en un elemento imprescindible de diversión masculina, acentuando su encanto por medio de las pocas virtudes que se le adjudican, el uso de los instrumentos en general y especialmente el de la flauta (símbolo fálico).

Finalmente, se debe destacar su posición de objeto estético, donde en efecto, una vez perdida su belleza, la sociedad las rechazará como meros parásitos (Souto, 2002).

Es importante destacar la prostituta de Menandro, el cual fue una gran influencia para la obra terenciana, esta hetera menandriana es más humana, debido a que se explican sus desgracias, en la siguiente cita, el investigador afirma que esta ya no es una prostituta, sino una a medias: "Si la pseudohetera puede tener una descripción favorable es por no ser realmente una prostituta sino una ciudadana convertida en tal (...) La prostituta real sigue existiendo y como tal continuará mereciendo una consideración claramente negativa” (Souto, 2002, p. 191).

Con base en estas últimas afirmaciones, podemos observar que la meretriz de la Hecyra no presenta, en su mayoría, las características generales de la prostituta griega, si bien hay alusiones a su avaricia, esta no es excesivamente lujuriosa, sexuada, ni mucho menos ebria y tampoco se apela a su "hábitat natural", los cuales son los banquetes.

Ya abarcados estos elementos de un núcleo general de la fórmula del sociograma en las comedias griegas medias y nuevas, podemos afirmar entonces, que Terencio, siempre matizando en su condición de sujeto transindividual, transforma la fórmula predicativa del núcleo sociogramático expuesto, y no lo desplaza, ya que se mantienen ciertos rasgos, como la condición de la avaricia y su discreción, pero se diferencia en que esta figura ya no será alcohólica, completamente amoral y lujuriosa, con una vida sumamente superflua y liberal, donde su espacio físico por defecto será en los banquetes, tampoco será animalizada, ni considerada una bestia cínica, tampoco una figura completamente negativa para la sociedad, además de esta diferenciación entre sociogramas, se insertan en La Suegra elementos de una hetera sensible, empática, agredida, portadora de bienestar y sacrificada, con un rol completamente contrario a las prostitutas anteriores, un rol de salvadora y restituidora del matrimonio, entendido como orden social. Estos elementos que se mantienen, se diferencian y se insertan, son los que aluden a una transformación de la fórmula predicativa del núcleo sociogramático de la prostituta terenciana.

\section{Conclusiones}

La figura de la prostituta siempre ha sido un tópico rodeado de muchos elementos discursivos, tanto en la literatura como en los discursos sociales. Ante esta pluralidad temática que se da en las figuras o sujetos de la sociedad, aportes como los del sociograma ayudan a ver estas configuraciones discursivas como un todo, y así poder analizar sus núcleos en referentes a la realidad como lo son el texto de ficción. En la Heycra de Publio Terencio Afro, efectivamente, se desprende un sociograma que, aunque posee relación, no corresponde del todo con los paradigmas de la figura de la prostitución de las comedias griegas. Por medio de la reafirmación, diferenciación e inclusión de elementos en el texto de Terencio, la fórmula del núcleo sociogramático es (re)inscrita para ser transformada. Si bien se mantienen elementos como la avaricia en la figura de estas mujeres, adjudicados por la voz masculina, es por este mecanismo de dar voz a la prostituta que Terencio inserta los elementos que transforman el sociograma, como la sensibilidad y la empatía, así también el desplazamiento y operación de signos con respecto a las comedias nuevas, donde la hetera terenciana ya no será lujuriosa, borracha, animalizada y perversa.

\section{Bibliografía}

Cros, E. (1986). "Introducción a la sociocrítica I y II”. Kañina. Revista de Artes y Letras de la Universidad de Costa Rica, X (1): 169-83.

Herreros, C. y Santapau, C. (2005). "Prostitución y matrimonio en Roma: ¿uniones de hecho o de derecho?”. Iberia: Revista de la Antigüedad, (8): 89-112. 
Navarro Martínez, V. (2016). "La hetera, ¿buena o mala? Un personaje secundario en el punto de mira de la comedia griega”. Tycho, 4: 167-184.

Montalbán, R., (2016). “El oficio más antiguo del mundo. Prostitución y explotación sexual en la Antigua Roma”. RAUDEM. Revista de Estudios de las Mujeres, (4): 155-177.

Robin, R. y Angenot, M. (1991). “La inscripción del discurso social en el texto literario”. En Malcunzynski, M. ed. Sociocríticas prácticas textuales: cultura de fronteras. Amsterdam: Rodopi.

Souto, F. (2002). "El rol de la prostituta en la comedia: De Ferécrates a Menadro”. Cuadernos de Filología Clásica: Estudios griegos e indoeuropeos, (12): 173-191.

Terencio, P. (1977). Comedias. México: Porrúa, S.A.

Alsina, J. n.d. "Comedia griega y comedia latina: A propósito del Miles Glorious”. Bachillerato, (3): $2-10$.

Cros, E. (2003). El sujeto cultural. Sociocrítica y psicoanálisis. Colombia: Eafit.

Fernández, L. (1975). "Comedia ática y sociedad ateniense III: los profesionales del amor en la comedia Media y Nueva”. Estudios Clásicos, (18): 59-88.

Herreros y Gónzalez C. (2001). "Las meretrices romanas: mujeres libres sin derechos”. Iberia: Revista de la Antigüedad, (4): 111-118.

Herreros y González. (2006). "Sequere me: tras la huella de las prostitutas en la antigua Roma”. En Barriobero, J. ed. España: Universidad de La Rioja, 70- 74.
Morenilla Talens, C. (1988), "El trasfondo de la alcahueta de la comedia griega”. En Joaquín Espinosa Carbonell; Emili Casanova Herrero. Coord. Homenatge a José Belloch Zimmermann. España: Universitat de València.

Manzano- Chinchilla, G. (2012). "La "no mujer": Categorización social de la prostituta libre en Roma”. Anesteria, (1): 29- 36.

Vargas, J. 2011. "El sociograma de la mujer en tres obras dramáticas de Mario Vargas Llosa (A propósito de La señorita de Tacna, Kathie y el hipopótamo y La Chunga)". Comunicación, 20 (1): 13-20. 